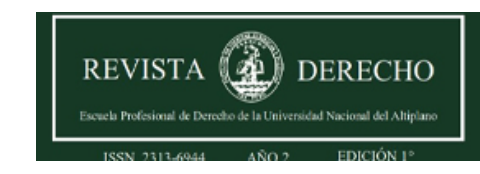

Revista de Derecho

ISSN: 2313-6944

ISSN: 2707-9651

revistaderecho@unap.edu.pe

Universidad Nacional del Altiplano

Perú

\title{
REGÍMENES LABORALES Y LA LEY SERVIR
}

De la Cruz Huanca, Oswaldo

REGÍMENES LABORALES Y LA LEY SERVIR

Revista de Derecho, vol. 5, núm. 2, 2020

Universidad Nacional del Altiplano, Perú

Disponible en: https://www.redalyc.org/articulo.oa?id=671870937004

DOI: https://doi.org/10.47712/rd.2020.v5i2.90

\section{(c) (1)}

Esta obra está bajo una Licencia Creative Commons Atribución 4.0 Internacional. 


\title{
REGÍMENES LABORALES Y LA LEY SERVIR
}

\author{
Labor regimes and serve law \\ Oswaldo De la Cruz Huanca \\ Dirección regional de salud, Perú \\ (iD https://orcid.org/0000-0001-5931-8943
}

DOI: https://doi.org/10.47712/rd.2020.v5i2.90
Redalyc: https://www.redalyc.org/articulo.oa?
id $=671870937004$

Recepción: 30 Septiembre 2020

Aprobación: 25 Octubre 2020

Publicación: 27 Octubre 2020

\section{Resumen:}

En la actualidad el derecho administrativo ha cobrado importancia, en merito a que el sistema laboral debe ser unificado según la Ley Servir, lo que sin duda amerita recurrir al campo del derecho. Los regímenes laborales son ciertamente difíciles de entender. Ante ello el derecho administrativo sancionador debe regular los parámetros idóneos; de ahí, es que existe una estrecha relación entre el derecho administrativo y el derecho laboral, entendido como norma de conducta que emana de la voluntad de todos, el cual debe ser aplicado en todos los regímenes laborales. Por lo que su idoneidad y eficacia debe aplicarse en todos los ámbitos laborales. PALABRAS CLAVE: derecho administrativo, derecho laboral, servidor público, régimen laboral.

\section{Abstract:}

At present, administrative law has gained importance, as the labor system must be unified according to the Servir Law, which undoubtedly merits resorting to the field of law. Labor regimes are certainly difficult to understand. In view of this, the administrative sanctioning law must regulate the suitable parameters; Hence, there is a close relationship between administrative law and labor law, understood as a standard of conduct that emanates from the will of all, which must be applied in all labor regimes. Therefore, its suitability and effectiveness must be applied in all work areas.

KEYWORDS: administrative law, labor law, public servant, labor regime.

\section{INTRODUCCIÓN}

El derecho admirativo como disciplina es fundamental, a su vez se debe precisar que el Perú, es un estado constitucional de derecho y democrático, el cual tiene como pilar el respeto de supremacía de la constitución política de Perú, en ese escenario el estado tiene la facultad de aplicar una sanción o pena a conductas contrarias al ordenamiento legal; esta facultad punitiva concebido como el ius puniendi, potestad del estado.

"en virtud de la cual está, revestida de un poderío o imperio, de clara punibilidad de determinados comportamientos que por su gravedad atentan contra la convivencia comunitaria y les impone penas y/o medidas de seguridad a título de consecuencia jurídica" (Velásquez citado en Villa Stein, 1998, p.93).

Esta facultad de sancionar puede darse mediante el derecho civil, derecho administrativo y el derecho penal, según su gravedad, en esta parte es pertinente resaltar el derecho administrativo sancionador que está comprendido en el derecho administrativo disciplinario, aplicable a conductas que lesionan el ámbito de la administración e impone sanciones administrativas. Al respecto "El Derecho Disciplinario, en tanto franja específica del Derecho Administrativo Sancionador, tiene entre sus objetivos corregir y optimizar el desempeño de los funcionarios y servidores públicos, de modo que el servicio a los destinatarios sea de calidad y no se vea perjudicado o desnaturalizado por acciones $\mathrm{u}$ omisiones que quebrantan el profesionalismo y la eficacia en el cumplimiento de los deberes y, por lo mismo, busca también evitar la incidencia en ámbitos de incompatibilidades y prohibiciones". (Rojas, 2012, p.758) 


\section{1.-Materiales y MÉtodos.}

En el presente trabajo se tomó en cuenta el método Cualitativo, que permitió realizar análisis e interpretación de textos, poniendo en algunos casos como ejemplos casos o hechos vinculados al derecho administrativo. Se utilizo las fichas de observación como instrumentos. No se considera muestreo, población, ni universo, porque es un artículo que rebasa el territorio nacional y regional.

\section{Relación Entre Servidor y Administración Pública}

Los servidores que se vinculan con la Administración Pública, a través de un contrato, mantienen una relación jurídica entre ambos la misma que se regirá por los términos y condiciones contenidos en la manifestación bilateral de voluntad que el contrato significa. Sin embargo, también, existe una relación especial del servidor público frente a la Administración el mismo que surge cuando el servidor público es investido de la función pública; interesa por ello, conocer y determinar cuál es la naturaleza jurídica de la relación que se establece entre el servidor público y la Administración Pública.

Los servidores públicos presentan una característica diferente de los demás ciudadanos, por la naturaleza jurídica de la relación jurídica establecida entre la Administración y los servidores públicos, esa relación entre el individuo y la Administración carece de proyección fuera del ámbito de la esfera administrativa de que se trate, pues mientras que en el procedimiento administrativo sancionador hablamos de una sujeción general donde el administrado es un infractor común, en el régimen disciplinario de las entidades públicas se habla de una especial sujeción donde el infractor es el funcionario o servidor público.

El Estado mantiene una relación singular con las personas que tienen un vínculo laboral con la misma que genera una unión más cercana entre el administrado y el Estado; al abordar el tema Lizárraga lo define:

La relación especial de sujeción es una institución que se refiere a aquellas personas que se encuentran más estrechamente unidas con la Administración, en tanto una vinculación laboral o subordinada, que genera una unión más cercana entre el administrado y el Estado. Proximidad que justifica el ejercicio del poder sancionador disciplinario en virtud de la relación jurídica surgida por la atribución de una función pública, que tiene por finalidad salvaguardar la moralidad y la ética de las relaciones que tienen lugar en el seno de la Administración. (Lizárraga, 2013, p.56)

3.- Responsabilidades de Distintas Ramas del Derecho que no son Excluyentes del Proceso Administrativo.

Al establecerse una relación de empleo entre el servidor público y la Administración Pública, se crea un vínculo jurídico que implica necesariamente deberes y derechos entre ambas partes. Si el servidor público transgrede los primeros, incurre en responsabilidad y se hace acreedor a sanciones.

La transgresión de los deberes jurídicos por parte del servidor público, significa la violación de la legalidad, puesto que dichos deberes le vienen señalados por la ley y pueden consistir en acciones u omisiones que producen efectos perjudiciales para la Administración o para el administrado, Salinas Siccha precisa que:

La Administración Pública en un Estado Democrático de Derecho está debidamente organizada por leyes, reglamentos y directivas que deben ser observadas y cumplidas por los funcionarios y servidores en el desempeño de sus actividades y labores al interior de la Administración. El quebrantamiento de aquellas normas, sin duda, acarrea responsabilidad administrativa, civil o dependiendo de la magnitud -hasta penalpor parte del sujeto público. (Salinas, 2011, pp.4-5)

La transgresión de un deber de la función puede consistir en la violación de las atribuciones o deberes que le impone la titularidad del cargo, o causar un daño patrimonial a la Administración o configurar un delito de carácter penal. A nivel jurídico existen pues, tres clases de responsabilidad: 
a) Administrativa: Es consecuencia de la infracción respecto de algún precepto que guía la gestión del funcionario o servidor público. La responsabilidad administrativa tendrá como consecuencia una sanción aplicada por la propia administración luego de un procedimiento administrativo de carácter disciplinario.

b) Civil: Es aquella responsabilidad referida a la afectación a los bienes o derechos del Estado o de terceros como consecuencia de la acción u omisión del empleado público. Tiene como consecuencia la obligación de indemnizar por los daños causados.

c) Penal: Es la que se genera como consecuencia de la comisión de delitos. En estos casos corresponde al Poder Judicial la aplicación de la sanción pertinente.

Las responsabilidades citadas no son excluyentes, o sea, un mismo hecho puede generar dos de esas responsabilidades, y a veces hasta tres, puesto que cada una tiene una finalidad específica distinta de las otras. De ellas nos interesa la disciplinaria o administrativa, en razón a que tanto la penal como la civil o patrimonial- tienen su regulación en otras ramas del Derecho. Tampoco abordamos la responsabilidad política, referido a la transgresión de deberes políticos propios de un cargo que sólo recae en el caso de empleados públicos de carácter político como podría ser el Presidente de la República o los Ministros de Estado.

\section{4.- Potestad Sancionadora de la Administración Pública}

El Estado, como ente jurídico y político, se encuentra dotado de funciones o atributos que le son propios y que se encuentran dirigidos al cumplimiento de determinados fines. Para lograr la realización de sus fines, el Estado tiene la necesidad de actuar y ejercer determinadas funciones para que sus diversas actividades se puedan cumplir, al margen de las funciones principales del Estado (ejecutivas, legislativas y judiciales), existe una función fundamental común a cada una de ellas: su función sancionadora, que es la llamada a esclarecer la regulación práctica de la libertad y de sus limitaciones, fijando un orden de convivencia a través de reglas de conducta en función del bien común.

Esta función sancionadora es el denominado "Ius puniendi", locución latina que se emplea para referirse a la potestad sancionadora que tiene el Estado "De forma desglosada encontramos por un lado que, la expresión "ius" equivale a decir "derecho", mientras que la expresión "puniendi” equivale a "castigar" y por tanto se puede traducir literalmente como derecho a penar o derecho a sancionar" (Wikipedia.org., s.f.), y así tradicionalmente la doctrina dominante ha venido entendiendo al Ius puniendi como derecho subjetivo, con intervención punitiva del Estado. En cambio, actualmente, algunos autores cuestionan tal naturaleza y prefieren hablar de un poder de castigar.

Es así que, acertadamente, modernas tendencias sostiene que la función punitiva del Estado se origina en su soberanía al identificar como punibles ciertas conductas y establecer la sanción correspondiente, por lo que esta función no puede concebirse como un derecho sino como una potestad no mediatizada por la forma jurídica, porque se busca regular las diferencias entre sujetos desiguales: por un lado, el Estado como aparato coercitivo con mayores prerrogativas; y por el otro, el ciudadano que se encuentra vulnerable ante las conductas prohibidas y debe someterse a las reglas administrativas predeterminadas.

Ahora bien, el Ius puniendi estatal, se manifiesta mediante dos sectores de actuación: el Derecho Penal y el Derecho Administrativo Sancionador, por lo que ambos gozan de una identidad de sustancia y de materia, donde los principios de la potestad sancionadora administrativa tienen base en los principios del Derecho Penal. Ello es así, pues principios como el de legalidad, ne bis in ídem, tipicidad, entre otros, son indudablemente aplicables al ámbito de la potestad sancionadora de la Administración Pública.

El modelo de Estado que postula nuestra sociedad es el de un Estado Constitucional de Derecho, donde:

El ordenamiento jurídico opera como ordenamiento-marco, estableciendo contenidos -tales como la dignidad humana, el reconocimiento de los derechos fundamentales, de la autonomía privada-, así como los fines culturales y sociales del Estado -y procedimientos- tales como el reconocimiento de la Democracia como consecuencia organizativa de la dignidad de la persona, división de poderes, sistema pluripartidista, entre otros. (Del Pozo, 2005, pp.64-65) 
Dentro de este modelo, el Estado dispone de la potestad administrativa disciplinaria como medio para reprimir aquellas conductas consideradas como ilícitos menores o que afecten bienes jurídicos que tienen poca relevancia respecto a los que son tutelados por el Derecho Penal, ya que este se rige por el Principio de última ratio, según el cual solo se puede recurrir al Derecho Penal en casos extremos([1]), por lo que antes es necesario agotar otras formas de control social. Esto es así porque la potestad de castigar que tiene el Estado (Ius puniendi) no solo se manifiesta en la persecución de delitos, realizados por el Ministerio Público y juzgados por el Poder Judicial, sino también por controles de menor jerarquía que se producen en el ámbito administrativo.

Las entidades de la Administración Pública tienen el reconocimiento de una potestad sancionadora específica, que se funda en un imperativo general de coerción, a fin de hacer cumplir los mandatos establecidos en las normas dirigidas a regular y/o determinar las conductas de los administrados frente al Estado. Esta potestad se considera como uno de los poderes más intensos que afectan la esfera de los derechos e intereses de los administrados, toda vez que implica la represión administrativa sobre las conductas infractoras que sean pasibles de producir la imposición de sanciones administrativas conforme a las causales expresamente señaladas en la Ley.

No esta demás precisar que todo ejercicio de la potestad administrativa debe ser realizado en estricta aplicación de la Ley del Procedimiento Administrativo General, normativa que regula y observa la actuación administrativa, consagrando el derecho al Debido Procedimiento, que garantiza a los administrados los derechos fundamentales para exponer sus argumentos, para ofrecer y producir pruebas y obtener una decisión motivada y fundada en derecho dentro de una tutela administrativa efectiva.

\section{Conclusiones}

Si bien es cierto que el 14 de setiembre del 2014 entra en vigencia la Ley $N^{\circ} 30057$ Ley de Servicio Civil y su Reglamento aprobado por el Decreto Supremo N 040-2014 PCM, norma que tiene como finalidad que los regímenes laborales deben regirse por un solo cuerpo legal, a la fecha no es así, en vista que muchas instituciones aún no se adecuan a la Ley Servir.

Cabe resaltar que el D.Leg. 276 es considerado como base sólida para comprender y aplicar el nuevo régimen disciplinario bajo la ley Servir. Sin embargo, sobre el particular debo indicar que el régimen disciplinario en la Ley Servir son mucho más garantistas, específicas y sistemáticamente ordenadas que el D. Leg. 276 y su reglamento, pues según lo estipulado en la Ley Servir ya no será necesario remitirse a otras normas para su comprensión, como cuando se hacía referencia a "autoridad competente" no logrando comprenderse quien era la persona que califica y aplica la sanción, mientras que con la entrada en vigencia de la Ley servir es preciso y claro en señalar que el órgano sancionador es el Jefe inmediato, siendo este la primera instancia para imponer sanciones de amonestación, en el caso de sanciones de suspensión lo es el jefe de Recursos Humanos y para las destituciones el titular de la entidad, siendo el Tribunal del Servicio Civil la segunda instancia.

Por otro lado, cabe precisar que el órgano instructor contará con la asistencia de un área de Secretaria Técnica integrada de preferencia por abogados designados en tal función, por lo que debo indicar que en este aspecto en particular y lo demás puntos la Ley Servir es claro respecto a quienes tienen competencia sancionadora. Con la nueva ley Servir desaparecen las Comisiones Permanentes de Procesos Administrativos Disciplinarios y a la vez desaparecen también los representantes de los trabajadores, quienes muchas veces actuaban como defensores del trabajador procesado, confundiendo su rol de defensor del Debido Procedimiento Administrativo. 


\section{Bibliografía}

Franco, E. R. (2015). El debido procedimiento administrativo- Derecho PUCP.

Guía sobre la aplicación del Principio- Derecho del Debido Proceso en los procedimientos administrativos. (agosto de 2013). Obtenido de Guía Minjus Final get. indd: https://www.minjus.gob.pe/wpcontent/uploads/2013/09/ Gu\%C3\%ADa-del-debido-proceso-MINJUS.pdf

Yucra, B. A. (2017). PROBLEMÁTICA DE LA DEFINICIÓN DE FUNCIONARIO Y SERVIDOR PUBLICO EN EL CODIGO PENAL PERUANO. Puno.

La Ley del Servicio Civil, Ley N³0057, https://www.servir.gob.pe/servicio-civil/ley-del-servicio-civil/

Regímenes laborales en el Perú, https://storage.servir.gob.pe/biblioteca/SERVIR\%20-\%20El\%20servicio\%20civil \%20peruano\%20-\%20Cap2.PDF

Decreto Supremo No 040-2014-PCM, que aprueba el Reglamento General de la Ley No 30057, Ley del Servicio Civil. https://storage.servir.gob.pe/archivo/Aprueban_Reglamento_General_de_la_Ley_30057.pdf

Implementación de la Reforma del Servicio Civil, https://storage.servir.gob.pe/servicio-civil/ Informe_implementacion_reforma_avances_y_logros_2014.pdf 